\title{
Programa Minha Casa Minha Vida (2012-2016): análise da eficiência relativa dos municípios brasileiros na execução de programas federais
}

\author{
Ludmila Ferreira Bandeira 1 \\ Edgar Reyes Junior 2 \\ ${ }^{1}$ Ministério do Desenvolvimento Regional / Secretaria Nacional de Habitação, Brasília / DF - Brasil \\ 2 Universidade de Brasília / Programa de Pós-Graduação em Administração, Brasília / DF - Brasil
}

\begin{abstract}
A presente pesquisa busca avaliar a eficiência relativa dos municípios brasileiros na execução do programa Minha Casa Minha Vida. Pretende-se que os resultados deste trabalho permitam a discussão de quais características ou fatores parecem afetar a eficiência municipal na implementação de políticas públicas, de forma a fornecer subsídios teórico-empíricos às pesquisas na área. O programa Minha Casa Minha Vida (MCMV), caso escolhido, compõe o eixo Infraestrutura Social e Urbana do Programa de Aceleração do Crescimento (PAC). O trabalho foi estruturado em duas etapas: a primeira é a classificação de municípios em grupos homogêneos; a segunda referese ao levantamento da eficiência relativa dos municípios na implementação do MCMV, por meio da aplicação de Análise Envoltória de Dados (DEA). Como resultado, foi identificado que os municípios brasileiros possuem padrões diversos de estruturação, sendo a maioria classificada como pouco estruturados ou com estrutura mínima, com claro padrão regional, em que Sul e Sudeste apresentam, com maior frequência, municípios bem estruturados em comparação com o Centro-Oeste, o Norte e o Nordeste. Ao analisar a eficiência relativa no MCMV, tendo como universo apenas os municípios que concluíram empreendimentos do PMCMV entre 2012 e 2016, os municípios com melhor estrutura também apresentaram melhores resultados, indicando que a estrutura deve ser determinante para o desempenho no programa. Em contrapartida, a análise regional apresentou o Centro-Oeste, o Norte e o Nordeste com mais municípios eficientes na execução do programa.
\end{abstract}

Palavras-chave: políticas públicas; eficiência relativa; avaliação de políticas públicas; Programa Minha Casa Minha Vida.

\section{Programa Minha Casa Minha Vida (2012-2016): análisis de la eficiencia relativa de los municipios brasileños en la implementación de programas federales}

Esta investigación tiene como objetivo evaluar la eficiencia relativa de los municipios brasileños en la implementación del programa Minha Casa Minha Vida (MCMV). Se pretende que los resultados de este trabajo permitan discutir qué características o factores parecen afectar la eficiencia municipal en la implementación de las políticas públicas, a fin de proporcionar apoyo teórico y empírico a la investigación en el área. El programa Minha Casa Minha Vida, si se elige, forma el eje de Infraestructura Social y Urbana del Programa de Aceleración del Crecimiento (PAC). El trabajo fue estructurado en dos etapas: la primera es la clasificación de los municipios en grupos homogéneos; la segunda se refiere al relevamiento de la eficiencia relativa de los municipios en la implementación del MCMV, mediante la aplicación del análisis de envoltura de datos (DEA). Como resultado, identificamos que los municipios brasileños tienen diferentes patrones de estructuración. La mayoría de ellos fueron clasificados como mal estructurados o mínimamente estructurados. Podríamos observar en los datos analizados un patrón regional claro, donde el Sur y el Sudeste tienen municipios mejor estructurados en comparación con el Centro Oeste, el Norte y el Noreste. Al analizar la eficiencia relativa en el MCMV, considerando como universo solo los municipios que completaron proyectos del PMCMV entre 2012 y 2016, los municipios mejor estructurados también presentaron mejores resultados, lo que indica que las condiciones estructurales pueden ser determinantes del desempeño del programa. En contrapartida, el análisis regional presentó el Centro Oeste, Norte y Nordeste con más municipios eficientes en la implementación del programa.

Palabras clave: políticas públicas; eficiencia relativa; evaluación de políticas públicas; Programa Minha Casa Minha Vida. 


\section{Minha Casa Minha Vida Program (2012-2016): analysis of the relative efficiency of Brazilian municipalities in the implementation of federal programs}

This research aims to evaluate the relative efficiency of Brazilian municipalities in the implementation of the Brazilian federal program for affordable housing Minha Casa Minha Vida (MCMV) program. The study discusses characteristics or factors that seem to affect municipal efficiency in policy implementation providing theoretical and empirical support to research in the area. The MCMV program is part of the Social and Urban Infrastructure axis of the Growth Acceleration Program (Programa de Aceleração do Crescimento - PAC). The work was divided into two stages. The first step is the classification of municipalities into homogeneous groups. The second refers to the municipalities' relative efficiency in the MCMV, through the application of data envelopment analysis (DEA). As a result, we identified that Brazilian municipalities have different structuring patterns. The majority of them were classified as poorly structured or minimally structured. In the analyzed data, we observed a clear regional pattern, where South and Southeast have more well-structured municipalities compared to the Central-west, North, and Northeast. By analyzing the relative efficiency in MCMV, considering as universe only municipalities that completed MCMV projects between 2012 and 2016, better-structured municipalities also presented better results, indicating that structural conditions may be determinants of program performance. In contrast, the regional analysis presented that Centralwest, North, and Northeast demonstrated efficient municipalities more often, on average, in implementing the program.

Keywords: public policy; relative efficiency; public policy evaluation; Minha Casa Minha Vida Program.

\section{INTRODUÇÃO}

Desde a promulgação da Constituição Federal de 1988 e ao longo da década de 1990, o contexto institucional brasileiro foi marcado por significativas transições, sobretudo no eixo das políticas sociais, cujas transformações estão associadas à transferência de um conjunto expressivo de atribuições e competências para os níveis subnacionais de governo (Lotta, Gonçalves \& Bitelman, 2014).

Havia grande expectativa de que o processo de descentralização levaria a uma provisão de bens e serviços públicos mais eficientes, elevando os níveis reais de bem-estar da população. Considerava-se que instâncias de poder mais próximas à população teriam mais e melhores mecanismos de participação social e, com isso, proveriam bens e serviços mais adequados às necessidades dos cidadãos.

No entanto, diversos estudos dedicados à análise do desempenho de municípios (E. Diel, F. Diel, Schuls, Chiarello \& Rosa, 2014; M. Silva, J. Silva, Borges, \& Souza, 2015; Varela, Martins \& Fávero, 2012) têm demonstrado que, além da grande variação dos níveis de prestação de serviços na esfera municipal, em sua grande maioria, os municípios analisados apresentaram baixa eficiência na implementação de políticas públicas.

Diante desse contexto, o presente artigo traz especial contribuição para o campo da avaliação de políticas públicas ao avaliar a eficiência relativa da administração municipal na implementação de políticas e programas federais. Assim, o trabalho busca apresentar insumos sobre os gargalos enfrentados pela esfera local na execução de políticas públicas.

A avaliação de políticas públicas tem sido tema recorrente das pesquisas no campo. Em análise bibliométrica dos periódicos nacionais de administração, Bandeira, R. Silva, Gonçalves e Calmon (2015) investigaram as publicações brasileiras no período de 2008 a 2013. Segundo os autores, quase $60 \%$ dos estudos analisados estão relacionados com as etapas das políticas públicas, sendo a maior parte focada na avaliação de políticas públicas, fato que endossa a importância do tema deste artigo. 
Além da relevância teórica do trabalho, demonstrada pelas contribuições no campo da avaliação das políticas públicas, o texto apresenta ainda relevância prática, uma vez que traz evidências sobre como a estrutura dos municípios pode influenciar os níveis de eficiência relativa deles na implementação do programa Minha Casa Minha Vida (MCMV).

O MCMV é um importante programa federal voltado para a produção de habitações de interesse social e compõe o eixo Infraestrutura Social e Urbana do Programa de Aceleração do Crescimento (PAC), sendo gerido pela Secretaria Nacional de Habitação do Ministério do Desenvolvimento Regional (MDR), em parceria com outras instituições.

O modelo inovador de coordenação de interesses na construção e implementação do programa Minha Casa Minha Vida é objeto de diversos estudos, contudo, poucas pesquisas se debruçaram sobre a atuação dos atores locais nesse processo, em especial os entes municipais.

As análises sobre a atuação dos municípios no programa tem sido alvo frequente de estudos de caso com enfoque estadual, como o caso da análise da dinâmica dos financiamentos habitacionais nos municípios do Rio Grande Sul (C. Silva \& Alves, 2014) e do impacto do programa MCMV no desenvolvimento da política habitacional nos municípios paulistas (Rolnik, Iacovini \& Klintowitz, 2014). Em ambos os exemplos, fica claro que o programa impactou significativamente a disponibilidade de recursos para habitação de interesse social.

No entanto, a análise empreendida nos municípios gaúchos concluiu que a implementação do programa não contribuiu para o surgimento de novos impulsionadores no financiamento habitacional na região. C. Silva e Alves (2014) destacam que a principal variável utilizada no processo de seleção - o déficit habitacional - não teve nenhum papel redistributivo na alocação de recursos entre os municípios.

Já no estudo dos municípios paulistas, Rolnik et al. (2014) concluíram que o MCMV pode ter contribuído para a desarticulação das iniciativas de planejamento habitacional empreendidas pelas prefeituras no âmbito da Companhia de Desenvolvimento Habitacional e Urbano do Estado de São Paulo (CDHU). Esse processo levou a redução da atuação municipal no setor a uma postura pragmática de captação de recursos federais, postura esta reproduzida pelos demais players da política habitacional, que incluem os movimentos sociais de moradia.

De forma mais sistêmica, existem estudos avaliativos sobre a gestão local dos recursos do programa nos municípios com população inferior a 50 mil habitantes. França (2015) destaca a importância do programa ao garantir acesso ao financiamento habitacional em municípios de pequeno porte, no entanto, atender às exigências para a obtenção de recursos federais ainda é um desafio para esses entes, em especial em razão da baixa capacidade técnica e institucional do poder público local.

Krause (2012) analisou o quadro institucional urbanístico e habitacional desses municípios. Seu estudo concluiu que a adoção dos instrumentos de planejamento habitacional previstos pelo Sistema Nacional de Habitação de Interesse Social (SNHIS), como plano, fundo e conselho voltados para a gestão da habitação de interesse social, era menos presente nas prefeituras que sediavam empreendimentos do Minha Casa Minha Vida. De alguma forma, o arranjo simplificado de operacionalização do programa contribuiu para a desarticulação de ações mais estruturadas da política habitacional em âmbito local. Esse resultado é complementado pela pesquisa realizada por Rolnik et al. (2014), que concluiu desdobramentos parecidos em outros portes de municípios no estado de São Paulo.

Isto posto, o presente artigo propõe avanços para essa agenda de pesquisa ao analisar as diferenças de eficiência na implementação do programa MCMV entre os diversos perfis de municípios brasileiros. Entender esse fenômeno corrobora tanto a relevância teórica quanto a relevância prática da pesquisa. 
Assim, ao perceber as potenciais contribuições da avaliação do desempenho municipal na execução de programas federais, como o programa Minha Casa Minha Vida, surge a seguinte pergunta de pesquisa: Qual é a eficiência relativa dos municípios brasileiros na implementação do programa Minha Casa Minha Vida? Pretende-se que a resposta à pergunta permita a discussão de quais características ou fatores parecem afetar essa eficiência dos municípios na implementação de políticas e programas, para fornecer subsídios teórico-empíricos às pesquisas na área.

\section{REFERENCIAL TEÓRICO}

\subsection{Avaliação de Políticas Públicas}

Souza (2003) resume o conceito de política pública como o campo do conhecimento que busca, ao mesmo tempo, "colocar o governo em ação" e/ou analisar essa ação (variável independente) e, quando necessário, propor mudanças no rumo ou curso dessas ações e/ou entender por que e como as ações tomaram determinado rumo em lugar de outro (variável dependente). Essa definição de políticas públicas dá subsídio à avaliação proposta, que busca considerar a implementação de políticas públicas pelos governos locais para, em seguida, investigar quais fatores afetam esses resultados, buscando analisar a ação do Estado.

É objetivo do presente artigo a avaliação da eficiência relativa dos municípios na implementação do programa Minha Casa Minha Vida (MCMV). Para tanto, faz-se necessário o levantamento do estado da arte da avaliação de políticas públicas.

Vedung (2010) define avaliação de políticas públicas como uma análise retrospectiva cuidadosa das intervenções do setor público, sua organização, conteúdo, implementação e resultados, que se destina a desempenhar um papel em futuras situações práticas.

Para Costa e Castanhar (2003), avaliação é o exame sistemático e objetivo de um projeto ou programa, finalizado ou em curso, que contemple seu desempenho, implementação e resultados. Para os autores, "o propósito da avaliação é guiar os tomadores de decisão, orientando-os quanto à continuidade, necessidade de correções ou mesmo suspensão de determinada política ou programa" (Costa \& Castanhar, 2003, p. 972).

A evolução da avaliação das políticas públicas como área de interesse dos pesquisadores do campo inicia-se na década de 1970. Para Vedung (2010), a avaliação de políticas públicas começa a ganhar popularidade nos anos 1990. Nesse período, toda a ação estatal fica sujeita à avaliação - parte-se do pressuposto de que, ao examinar cuidadosamente os resultados das ações empreendidas e os caminhos em direção a elas, o decisor estaria mais bem preparado para orientar ações subsequentes. Em resumo, "a avaliação é um instrumento importante para a melhoria da eficiência do gasto público, da qualidade da gestão, do controle social sobre a efetividade da ação do Estado" (Ramos \& Schabbach, 2012, p. 1272) e tem por objetivo nortear a tomada de decisão, provendo informação para subsidiar escolhas que envolvam definição de ações e alocação de recursos.

É importante salientar que governo e administração pública têm uma longa trajetória na busca de se munirem com indicadores e índices para medir e avaliar o desempenho das ações públicas, contudo, é só a partir dos anos 1960 e 1970 que essas técnicas de avaliação passam a ganhar relevância em escala internacional. Nesse contexto, Howlett, McConnell e Perl (2016) reforçam que é nos anos 1970 que 
pesquisadores em muitos países iniciam estudos sobre a ligação entre as falhas na implementação de políticas públicas e seu sucesso.

Assim, ainda que o estudo sobre políticas públicas como análise do Estado em ação tenha iniciado na década de 1930, Oliveira (2016) salienta que é nos anos 1970 que os estudos abandonam seu caráter estritamente normativo e passam a avaliar tais políticas em termos de eficiência e efetividade, direcionando esforços para o alcance de metas.

Nesse sentido, cabe conceituar, brevemente, as três dimensões da avaliação de políticas públicas. Para Januzzi (2005), essas dimensões avaliativas buscam o acompanhamento das ações estatais, quanto ao uso dos recursos, quando se trata de eficiência, quanto ao cumprimento de metas, ao tratar a eficácia e quanto aos desdobramentos sociais mais abrangentes e perenes, na avaliação da efetividade.

Sano e Montenegro (2013) corroboram essas definições entendendo que a efetividade é percebida mediante a avaliação das transformações ocorridas com base na ação, a eficácia resulta da relação entre metas alcançadas versus metas pretendidas e a eficiência significa fazer mais com menos recursos.

Nesse contexto, o presente trabalho tem por objetivo a avaliação da eficiência relativa, por meio da análise dos insumos utilizados para realização do programa. Os municípios foram analisados com base na gestão do tempo e dos recursos financeiros alocados, conforme detalhado na metodologia de pesquisa.

\subsection{Programa Minha Casa Minha Vida (MCMV)}

O programa Minha Casa Minha Vida (MCMV), assim como todas as políticas habitacionais históricas do Brasil, "tem como carro-chefe a promoção de um bem: a casa própria" (Dutra, 2013, p. 131). Esse processo conta com o protagonismo do Estado na captação de recursos, financiamento, produção e comercialização das habitações.

Dutra (2013) explica que a política habitacional brasileira, como política de promoção do estado de bem-estar social (welfare state), baseou-se no modelo norte-americano, que estava ancorado em valores liberais, razão pela qual a atuação do estado está restrita às ações regulatórias do sistema habitacional, sem nenhuma interferência estatal nas relações de compra, venda ou financiamento. Nesse modelo, o financiamento é viabilizado por associações de poupança e empréstimo privadas e as unidades habitacionais destinadas às famílias de baixa renda são parcialmente subsidiadas, de modo a estimular a atuação do setor privado no segmento.

Klintowitz (2016) explica que, com a eleição do presidente Lula, os movimentos populares de moradia passaram a ser reconhecidos como players do setor, com a conformação de uma estratégia de coordenação de interesses ousada, capaz de colocar na mesa de negociação movimentos de moradia e setor produtivo, coalizões com interesses historicamente opostos. Assim, nasce o programa habitacional Minha Casa Minha Vida, um programa situado "entre o direito à moradia e reestruturação do setor produtivo" (Klintowitz, 2016, p. 167).

A retomada da habitação de interesse social à agenda federal tem como importante marco a criação do Ministério das Cidades, em 2003, que passa a ser titular da Política de Desenvolvimento Urbano em âmbito nacional. O ministério destacou em sua estrutura uma secretaria finalística voltada para o planejamento e a implementação da Política Nacional de Habitação (PNH).

No entanto, apenas em 2007, a provisão de habitação de interesse social passa a receber protagonismo no orçamento federal, sendo composta, basicamente, por quatro tipos de financiamento 
federal. Menezes (2017) esclarece que a primeira forma de financiamento adotada pelo programa foi realizada por meio do Fundo Nacional de Habitação de Interesse Social (FNHIS), por intermédio do Programa de Aceleração do Crescimento (PAC) 1, entre 2007 e 2009. No período de 2009 a 2016, foram utilizados o Fundo de Desenvolvimento Social (FDS), o Fundo de Arrendamento Residencial (FAR) e o Orçamento Geral da União (OGU), por meio de três modalidades do programa Minha Casa Minha Vida (MCMV): o Entidades, o Empresarial (faixa 1) e o Oferta Pública de Recursos (OPR).

A Política Nacional de Habitação conta com vasto arcabouço institucional normativo que inclui o direito à moradia garantido como um direito social na Constituição Federal (Emenda Constitucional $n^{\circ}$ 26/2000), a Política Nacional de Habitação (PNH - Lei no 11.124/2005) e o Plano Nacional de Habitação (PlanHab), cujo objetivo é traçar uma estratégia para o equacionamento das demandas do setor de habitação em 15 anos a partir de sua publicação (2009).

A PNH prevê tanto um sistema para provisão de habitação digna à população de baixa renda, por meio do Sistema Nacional de Habitação de Interesse Social (SNHIS) e dos Planos Locais de Habitação de Interesse Social (PLHIS), quanto a expansão da oferta de imóveis e crédito para a população com capacidade de arcar com financiamento imobiliário por meio do Sistema Nacional de Mercado. É importante salientar que o modelo da $\mathrm{PNH}$ propõe diversas instâncias de participação social, incluindo o Conselho das Cidades, em âmbito nacional, e os conselhos estaduais, distritais e municipais, que têm atribuições específicas relativas às questões urbanas e habitacionais.

Klintowitz (2016) destaca ainda que a conjuntura econômica foi determinante para a ampliação dos mecanismos e do volume de recursos destinados ao setor habitacional, por meio do MCMV, que teve, entre outros, o objetivo de socorrer o setor produtivo da construção civil e o mercado imobiliário e evitar o aprofundamento da crise do mercado.

Segundo dados do Ministério da Economia (Ministério do Planejamento, 2014), entre 2009 e 2014, foram investidos R 251,8 bilhões no MCMV, considerando os subsídios diretos e as linhas de crédito disponibilizadas, permitindo a contratação de 3,75 milhões de unidades habitacionais em todo o Brasil. Aguiar (2015) avalia que o MCMV tem sido operacionalizado com base na lógica das empresas privadas do setor imobiliário, deixando pouco espaço de influência ao poder público, em especial quanto a decisões de implantação dos empreendimentos.

Ademais, o MCMV foi lançado em 2009 para criar mecanismos que incentivem a produção e aquisição de novas unidades habitacionais ou a requalificação de imóveis urbanos e a produção ou reforma de habitações rurais, para famílias com renda mensal de até R\$ 5 mil. Esse programa compreende o Programa Nacional de Habitação Urbana (PNHU) e o Programa Nacional de Habitação Rural (PNHR).

O MCMV, integrado ao PNHU, possui três modalidades: a modalidade Financiamento com Recursos do Fundo de Garantia do Tempo de Serviço (FGTS), a modalidade Aquisição e Alienação de Imóveis, por meio da transferência de recursos ao Fundo de Arrendamento Residencial (FAR) e o programa Minha Casa Minha Vida - Entidades (MCMV-E), com operações realizadas com recursos provenientes do Fundo de Desenvolvimento Social (FDS) (Reis, 2013).

A complexidade de fontes de financiamento, as modalidades de apoio no âmbito do programa e a quantidade de players envolvidos demonstram o modelo inovador de coordenação de interesses na construção e implementação do programa Minha Casa Minha Vida.

A literatura levantada nesta seção demonstrou que muitos estudos se dedicaram à compreensão da configuração institucional do MCMV, no entanto, poucas pesquisas se debruçaram sobre a atuação dos atores locais nesse processo, em especial dos entes municipais. 


\section{MÉTODOS}

A pesquisa realizada pode ser delineada como de caráter descritivo e quantitativo, uma vez que seu objetivo central é avaliar a eficiência relativa dos municípios brasileiros na execução do programa Minha Casa Minha Vida. A pesquisa descritiva busca apresentar as características de determinado fenômeno ou população, bem como o estabelecimento de relações entre variáveis e fatos.

A presente pesquisa foi realizada em duas etapas. Na primeira, foi feita a classificação dos 5.570 municípios brasileiros em grupos homogêneos e comparáveis, por meio da técnica Análise Classificatória. Foi utilizado um algoritmo de classificação tradicional, como definido em Carvalho, Mata e Resende (2007), quando são agrupadas unidades geográficas do tipo municípios independentemente de sua localização, em atenção ao conjunto de características comuns.

Para classificar os municípios brasileiros em clusters, foram utilizados dados da pesquisa Informações Básicas Municipais (Munic), de 2015. A unidade de investigação da Munic é o município, sendo a Prefeitura o informante principal, por meio dos diversos setores que a compõem. Apesar das informações declaradas por município, a pesquisa é a principal fonte de informações sobre os municípios brasileiros.

Dado o objeto da presente pesquisa, optou-se pela utilização de informações relativas ao planejamento urbano (Bloco 2) e aos recursos para gestão (Bloco 3) como variáveis para a classificação de municípios. Do Bloco 2 foram analisadas as variáveis relativas ao plano diretor (existência, ano da lei de criação e ano da última atualização). Essas variáveis foram transformadas na variável Perfil do Plano Diretor, que foi subdividida em três categorias:

- Plano diretor atualizado - quando o município possui um plano diretor criado ou atualizado em 2010 ou após esse ano.

- Plano diretor desatualizado - quando o município possui um plano diretor criado ou atualizado em data anterior a 2010.

- Não possui plano diretor - quando o município declarou não possuir plano.

Do Bloco 3 foram analisadas características relacionadas com as taxas instituídas (taxa de iluminação pública, taxa de coleta de lixo, taxa de incêndio ou combate a sinistros, taxa de limpeza urbana, taxa de poder de polícia e outros tipos de taxa). Essas variáveis também foram transformadas na variável Perfil das Taxas Instituídas, a qual subdividiu-se em duas categorias:

- Mais de 3 taxas - quando o município possui pelo menos 3 taxas instituídas.

- Menos de 3 taxas - quando o município possui menos de 3 taxas instituídas.

Dada a necessidade de utilização de dados categóricos disponibilizados pela Pesquisa Munic, foi necessário o emprego de um algoritmo variante do k-means, o método k-modes, que estende o paradigma k-means para o agrupamento de dados categóricos ao trocar a média de clusters com a moda, fazendo uso de novas medidas de dissimilaridade para tratar com objetos categóricos e adaptando o método à análise de frequência para atualizar as modas dos clusters (Carlantonio, 2001).

Essa etapa viabilizou a adequação dos dados para a realização da segunda etapa da pesquisa, a aplicação da técnica Análise Envoltória de Dados (Data Envelopment Analysis, DEA). O uso do DEA 
demanda a identificação dos municípios com perfis similares, pois, no modelo proposto, eles serão as Unidades Tomadoras de Decisão (Decision Maker Units, DMUs), que precisam ser homogêneas por premissa do modelo. Essa etapa tem por objetivo a identificação dos municípios que possuem a melhor eficiência relativa na execução do MCMV.

De acordo com Lins, Lobo, Silva, Fiszman \& Ribeiro (2007), Peña (2008) e Pedroso, Calmon, Bandeira e Lucena (2012), o método DEA é uma metodologia não paramétrica para a mensuração comparativa da eficiência de Unidades Tomadoras de Decisão (Decision Making Units, DMUs), com base nas melhores práticas.

Esse Método pode ser utilizado para avaliar a eficiência técnica de unidades produtivas, que utilizam múltiplos insumos para produzir múltiplos bens e/ou serviços medidos em diferentes unidades. [...]. O Método compara os insumos e os produtos de cada unidade e determina os índices de eficiência relativa de cada unidade analisada (Peña, 2008, p. 84).

Assim, a análise envoltória de dados é um método não paramétrico para a definição da fronteira de eficiência. Peña (2008) e Lins et al. (2007) ressaltam ainda que o método DEA tem sido aplicado com sucesso no estudo da eficiência da administração pública e em organizações sem fins lucrativos, razão pela qual justifica-se a escolha do método para a análise da eficiência relativa alcançada pelos municípios na implementação do programa Minha Casa Minha Vida.

A presente proposta apresenta o benchmark dos municípios brasileiros na execução do MCMV, por meio de indicadores de resultado (outputs), que consideram como insumos (input) os recursos financeiros investidos e o tempo empregado na construção das Unidades Habitacionais (UHs) do programa, sendo as UHs o resultado, ou output, do modelo.

As DMUs selecionadas para o estudo foram os 619 municípios que concluíram empreendimentos do programa Minha Casa Minha Vida financiados com recursos do Fundo de Arrendamento Residencial (FAR), no período de 2012 a 2016, entendidos como Unidades Tomadoras de Decisão (DMU) autônomas. Estas desempenham funções de gestão descentralizada semelhantes que são mensuradas por uma metodologia homogênea e, portanto, são comparáveis.

A definição pelo modelo com retornos variáveis de escala, de acordo com o objetivo proposto e a literatura sobre o tema, deve-se ao fato de que, em geral, as relações que se estabelecem na gestão de programas e políticas públicas não pressupõem retornos constantes de escala. Tal modelo utiliza a fronteira variable returns to scale (VRS), que considera rendimentos variáveis de escala.

Dados os objetivos da proposta e a característica do processo de seleção de empreendimentos a serem apoiados pelo programa, o modelo a ser aplicado terá orientação input, para que se possa definir quais municípios utilizam de forma mais racional seus insumos para a produção das unidades habitacionais do programa Minha Casa Minha Vida. A análise dos resultados foi classificada em quatro níveis de eficiência, com base no escore de eficiência apresentado pelo município, tal como detalhado no Quadro 1. 


\section{QUADRO 1 NÍVEIS DE EFICIÊNCIA RELATIVA NA IMPLEMENTAÇÃO DO PROGRAMA MCMV}

\begin{tabular}{lcc} 
Classificação & Escore () & Caracterização \\
\hline Eficiência & $\Sigma=1$ & Eficiência igual a 100\% \\
Baixa ineficiência & $1,01 \leq \Sigma<1,10$ & Ineficiência entre 1\% e 10\% \\
Média ineficiência & $1,10 \leq \Sigma<1,25$ & Ineficiência entre $10 \%$ e $25 \%$ \\
Alta ineficiência & $1,25 \leq \Sigma$ & Ineficiência igual ou superior a 25\%
\end{tabular}

Fonte: Elaborado pelos autores.

Nessa etapa, serão usados basicamente dados de fontes secundárias. Para definir os recursos financeiros consumidos/dispostos pelos municípios e os resultados alcançados na execução do programa (unidades habitacionais entregues, prazo de execução etc.) serão utilizados dados do monitoramento do programa disponibilizados pela Secretaria Nacional de Habitação do Ministério do Desenvolvimento Regional (SNH/MDR).

\section{RESULTADOS}

\subsection{Análise Classificatória de Municípios}

Nessa etapa, os 5.570 municípios brasileiros foram classificados, por meio da técnica Análise Classificatória (Cluster Analysis), de acordo com dois critérios relacionados com a capacidade de planejamento e arrecadação de impostos dos municípios. Como resultado, chegou-se à definição de 6 grupos com base na combinação de perfis de taxas instituídas e plano diretor. A Tabela 1, a seguir, apresenta de forma resumida a distribuição de municípios resultados dessa classificação.

\section{TABELA 1 DISTRIBUIÇÃO DOS MUNICÍPIOS POR PERFIL DO PLANO DIRETOR E PERFIL DE TAXAS INSTITUÍDAS}

\begin{tabular}{|c|c|c|c|c|c|}
\hline $\mathrm{N}^{\circ}$ & Nome do grupo & $\begin{array}{l}\text { Perfil de taxas } \\
\text { instituídas }\end{array}$ & Perfil do plano diretor & $\begin{array}{c}\text { Qtd. de } \\
\text { municípios }\end{array}$ & $\%$ \\
\hline 1 & Muito bem estruturados & Mais de 3 taxas & PD atualizado & 354 & $6 \%$ \\
\hline 2 & Bem estruturados & Menos de 3 taxas & PD atualizado & 808 & $15 \%$ \\
\hline 3 & Medianamente estruturados & Mais de 3 taxas & PD desatualizado & 450 & $8 \%$ \\
\hline 4 & Pouco estruturados & Menos de 3 taxas & PD desatualizado & 1.145 & $21 \%$ \\
\hline 5 & Muito pouco estruturados & Mais de 3 taxas & Não possui PD & 420 & $8 \%$ \\
\hline \multirow[t]{2}{*}{6} & Estrutura mínima & Menos de 3 taxas & Não possui PD & 2.393 & $43 \%$ \\
\hline & & Total & & 5.570 & $100 \%$ \\
\hline
\end{tabular}

Fonte: Elaborada pelos autores. 
O grupo com a maior quantidade de municípios é o Grupo 6 - aqueles com estrutura mínima -, que também possui o perfil mais crítico, uma vez que não têm plano diretor, além de terem menos de três taxas instituídas. Enquadram-se nesse perfil $43 \%$ das cidades brasileiras. Cabe ressaltar que mais da metade delas não possui plano diretor, que é considerado, por muitos autores, um instrumento básico da política de desenvolvimento do município.

O segundo maior grupo refere-se ao conjunto de municípios com plano diretor desatualizado e menos de três taxas instituídas. Esse grupo é composto por 1.145 municípios, o que representa cerca de $20 \%$ do total. Essas localidades encontram-se em situação ligeiramente melhor que o grupo anterior, pois, pelo menos, contam com o instrumento de planejamento, ainda que desatualizado. No entanto, surpreende que 18 dos maiores municípios brasileiros tenham sido enquadrados nesse grupo - esse valor representa mais de $40 \%$ das cidades com o porte populacional superior a 500 mil habitantes (41 municípios).

Outro ponto a ser destacado é que o grupo com o perfil considerado mais desejável possui apenas 354 municípios, representando 6\% do total. Somente esses municípios têm plano diretor atualizado e mais de três taxas instituídas. Apenas 4 municípios com população superior a 500 mil habitantes foram enquadrados nesse perfil, o que representa menos de $10 \%$ dos municípios com esse porte populacional.

Quando passamos para uma análise georreferenciada das informações, percebe-se que os desafios de estruturação dos municípios acompanham claramente os problemas de desigualdade regional. $\mathrm{O}$ mapa a seguir (Figura 1) mostra a representação das variáveis por cartograma, revelando as variáveis por meio dos polígonos dos municípios.

\section{FIGURA 1 MAPA COM DISTRIBUIÇÃO DOS MUNICÍPIOS POR PERFIL DO PLANO DIRETOR E PERFIL DE TAXAS INSTITUÍDAS}

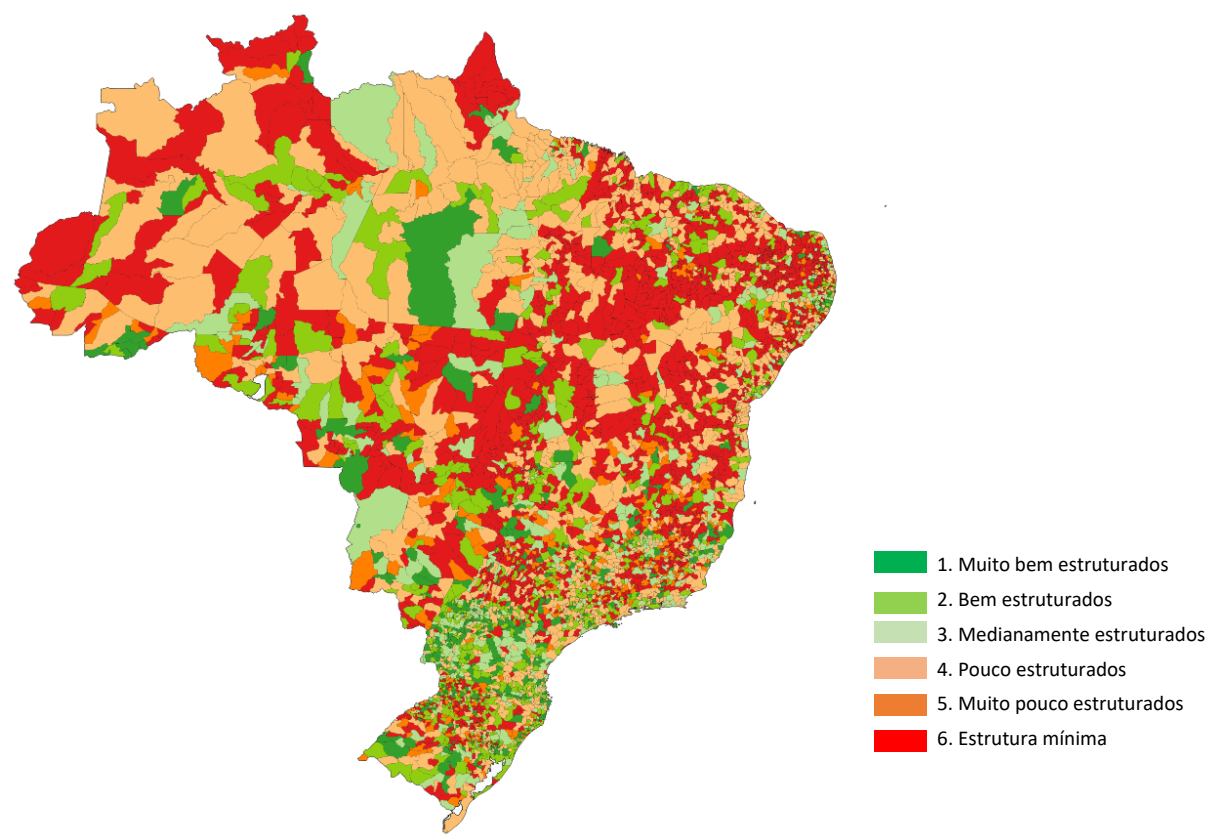

Fonte: Elaborada pelos autores. 
A análise que considera as bases geográficas revela que, de modo geral, os municípios das regiões Sul e Sudeste e do litoral brasileiro ocuparam os grupos mais estruturados, enquanto os municípios do interior, em especial das regiões do Sertão nordestino e o norte e o nordeste do estado de Minas Gerais foram classificados, em sua maioria, como municípios de pouca estrutura ou com estrutura mínima, o que torna evidente a importância de políticas públicas de incentivo à estruturação dos municípios que levem em consideração algum tipo de recorte regional.

Essa análise revela a clara necessidade de se implementarem políticas públicas com recorte regional, incentivando, de forma adequada, a estruturação do planejamento municipal, uma vez que $51 \%$ dos municípios brasileiros não possuem plano diretor e $29 \%$ possuem planos desatualizados. Esse resultado é preocupante, visto que a legislação brasileira, por meio do Estatuto da Cidade (Lei no 10.257/2001), prevê a obrigatoriedade da elaboração de planos diretores para municípios:

I - com mais de 20 mil habitantes;

II - integrantes de regiões metropolitanas e aglomerações urbanas;

III - onde o poder público municipal pretenda utilizar os instrumentos previstos no $\$ 4^{\circ} \mathrm{do}$ art. 182 da Constituição Federal;

IV - integrantes de áreas de especial interesse turístico;

$\mathrm{V}$ - inseridos na área de influência de empreendimentos ou atividades com significativo impacto ambiental de âmbito regional ou nacional;

VI - incluídos no Cadastro Nacional de Municípios com áreas suscetíveis à ocorrência de deslizamentos de grande impacto, inundações bruscas ou processos geológicos ou hidrológicos correlatos (art. 41 da Lei no 10.257/2001).

Além da obrigatoriedade da elaboração de planos diretores para a maior parte dos municípios, a lei prevê a necessidade de atualização desse instrumento pelo menos a cada dez anos $\left(\$ 3^{\circ}\right.$, art.40 da Lei $\left.n^{\circ} 10.257 / 2001\right)$, sob pena de responsabilização dos gestores por crime de improbidade administrativa diante do não cumprimento da norma. No entanto, esse arcabouço legal parece ser insuficiente para estimular os municípios a elaborarem seu principal instrumento de planejamento urbano, demonstrando, por meio de dados da Tabela 1, como o poder público local tem sido negligente com esse instrumento fundamental para a organização das cidades.

Esse resultado dialoga com questões sobre o processo de descentralização levantadas no referencial teórico e na justificativa da pesquisa. Uma das consequências do processo de descentralização brasileiro foi a acentuada assimetria na disponibilidade de recursos entre os municípios, refletindo dificuldades em promover uma descentralização fiscal que não reforce as desigualdades regionais. Rezende (1997) salienta como potenciais causas dessa assimetria duas características: a) a concentração da base produtiva, limitando as possibilidades de geração de recursos próprios de forma suficiente a atender às demandas da população e b) uma visão estereotipada das desigualdades regionais, com base em critérios de rateio das partilhas de receita e das transferências compensatórias, que não consideram as desigualdades intrarregionais.

$\mathrm{Na}$ análise dos subsistemas da gestão pública municipal realizada por Veloso, Monasterio, Vieira e Miranda (2011), foi diagnosticada que a prática da terceirização tem sido recorrente na 
gestão financeira das prefeituras. Os pequenos municípios (43\%) são aqueles que mais recorrem a serviços externos de contabilidade. Há também um padrão regional bem definido, que ocorre com mais frequência na região Nordeste. Apesar de a terceirização ser usualmente defendida com base na eficiência e na flexibilidade, há evidências de que a gestão financeira terceirizada compromete a boa gestão municipal. Tal fato explica a predominância da classificação com capacidade de planejamento e arrecadação comprometida dos municípios do interior e das regiões Norte e Nordeste.

A Figura 2 apresenta a distribuição dos municípios por perfil do plano diretor e perfil de taxas instituídas e região. Os municípios que compõem o Grupo 6 - Estrutura mínima - foram assinalados em vermelho. Ao analisar conjuntamente as Figuras 1 e 2, vê-se claramente o predomínio desses municípios no interior das regiões Norte, Nordeste e Centro-Oeste. A maior parte desses municípios possui porte populacional de até 50 mil habitantes, apenas 12 municípios desse grupo possuem população entre 50 mil e 500 mil habitantes. Esse fato pode facilmente ser associado a outros pontos: municípios menores, em geral, possuem menores fontes de arrecadação e estruturas de gestão, o que dificulta seu planejamento e atribuições legais.

\section{FIGURA 2 DISTRIBUIÇÃO DOS MUNICÍPIOS POR PERFIL DO PLANO DIRETOR E PERFIL DE TAXAS INSTITUÍDAS E REGIÃO}

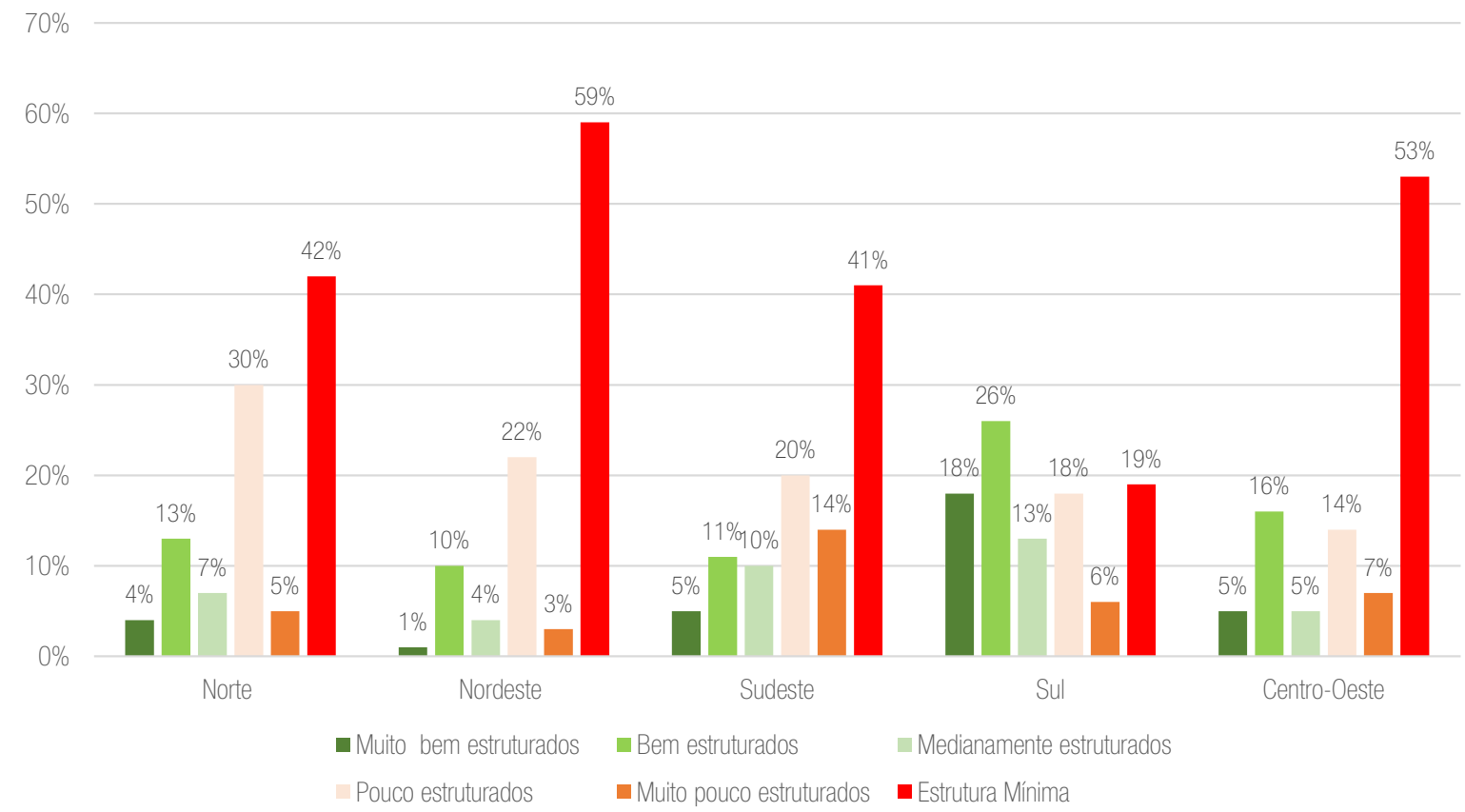

Fonte: Elaborada pelos autores. 
Vale ressaltar também o desempenho da região Sul, em especial do estado do Paraná, onde predominaram perfis de municípios que possuem plano diretor atualizado. Seguindo também as tendências de desenvolvimento, percebe-se que os municípios da Região Litorânea apresentaram, com mais frequência, o perfil mais desejável do que os municípios do interior.

A análise por porte populacional, apresentada na Figura 3, demonstrou que quanto maior o porte populacional dos municípios menor a frequência de municípios muito pouco estruturados ou com estrutura mínima. Contudo, os municípios com porte populacional entre 100 e 500 mil habitantes foram os que apresentaram melhor frequência de municípios com estrutura mediana ou superior, evidenciando que os municípios muito pequenos são pouco viáveis em termos de estrutura e os municípios demasiadamente grandes também enfrentam desafios significativos para alcançar boas condições de estrutura, havendo um aparente equilíbrio nos municípios de porte populacional mediano (entre 100 e 500 mil habitantes).

\section{FIGURA 3 DISTRIBUIÇÃO DOS MUNICÍPIOS POR PERFIL DO PLANO DIRETOR E PERFIL DE TAXAS} INSTITUÍDAS E PORTE POPULACIONAL

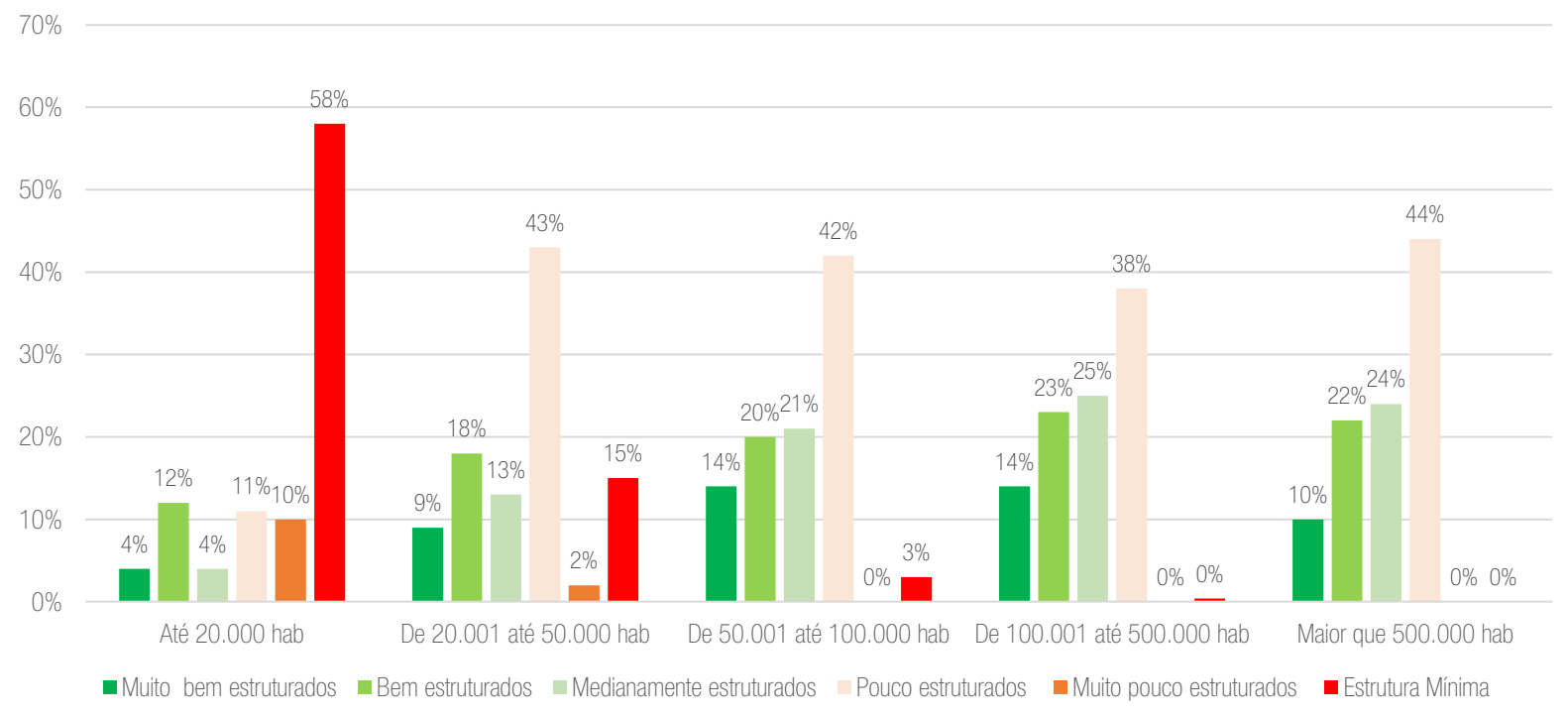

Fonte: Elaborada pelos autores.

\subsection{Avaliação da eficiência relativa dos municípios na implementação do programa MCMV}

Para análise da eficiência relativa dos municípios brasileiros selecionou-se o conjunto de municípios que concluíram empreendimentos do programa Minha Casa Minha Vida no período de 2012 a 2016.

No modelo DEA foram utilizadas três variáveis: unidades habitacionais entregues, tempo médio de conclusão de empreendimentos e valor do investimento. Apresentamos suas medidas de dispersão na Tabela 2, para melhor visualização das variáveis e compreensão de seu comportamento. 


\section{TABELA 2 MEDIDAS DE DISPERSÃO DAS VARIÁVEIS QUE COMPÕEM O MODELO DEA PARA AVALIAÇÃO DA EFICIÊNCIA RELATIVA DE MUNICÍPIOS EFICIENTES NO MCMV POR PERFIL DO PLANO DIRETOR E PERFIL DE TAXAS INSTITUÍDAS}

\begin{tabular}{|c|c|c|c|c|c|}
\hline \multirow[b]{2}{*}{ Variáveis do modelo DEA } & \multirow[b]{2}{*}{$\begin{array}{l}\text { Medidas de } \\
\text { dispersão }\end{array}$} & \multicolumn{4}{|c|}{ Cluster de municípios } \\
\hline & & $\begin{array}{l}\text { Muito bem } \\
\text { estruturados }\end{array}$ & $\begin{array}{c}\text { Bem } \\
\text { estruturados }\end{array}$ & $\begin{array}{l}\text { Medianamente } \\
\text { estruturados }\end{array}$ & $\begin{array}{c}\text { Pouco } \\
\text { estruturados }\end{array}$ \\
\hline \multirow{4}{*}{$\begin{array}{l}\text { Unidades Habitacionais } \\
\text { Entregues }\end{array}$} & Mínimo & 33 & 30 & 20 & 61 \\
\hline & Média & 999 & 1.531 & 1.660 & 1.475 \\
\hline & Máximo & 4.455 & 30.003 & 16.898 & 11.087 \\
\hline & Desvio padrão & 963 & 3.259 & 2.444 & 1.812 \\
\hline \multirow{4}{*}{$\begin{array}{l}\text { Tempo médio de } \\
\text { conclusão (em dias) }\end{array}$} & Mínimo & 406 & 365 & 526 & 405 \\
\hline & Média & 789 & 920 & 888 & 896 \\
\hline & Máximo & 1.743 & 2.072 & 2.248 & 2.270 \\
\hline & Desvio padrão & 231 & 307 & 269 & 274 \\
\hline \multirow{4}{*}{$\begin{array}{l}\text { Valor de investimento } \\
\text { (em R\$) }\end{array}$} & Mínimo & 1.844 .700 & 1.049 .972 & 1.180 .000 & 3.279 .600 \\
\hline & Média & 50.224 .875 & 80.977 .197 & 84.786 .681 & 76.877 .477 \\
\hline & Máximo & 245.339.159 & 1.727 .766 .583 & 859.580 .914 & 615.634 .554 \\
\hline & Desvio padrão & 50.114 .356 & 178.227 .654 & 127.052 .451 & 97.093 .528 \\
\hline
\end{tabular}

Fonte: Elaborada pelos autores.

Chama atenção o valor máximo de quase $\mathrm{R} \$ 2$ bilhões no cluster de município bem estruturados - esse valor corresponde à produção de mais de 30 mil unidades habitacionais na cidade do Rio de Janeiro/RJ (330455), apresentando um valor médio de pouco mais de $\mathrm{R} \$ 50$ mil por unidade habitacional.

Os maiores valores máximos de investimento são observados nos municípios bem estruturados e medianamente estruturados, o que pode ser explicado pelo fato de boa parte dos municípios mais populosos estarem classificados nesses clusters. Esses municípios possuem grande demanda por habitação popular, razão pela qual recepcionaram mais empreendimentos do MCMV no período. De forma geral, os valores mais altos de investimento são associados à maior quantidade de unidades habitacionais entregues. Tal fato é justificado pelos limites de financiamento por unidade, estabelecidos nos normativos do programa.

No entanto, ao examinarmos os prazos de conclusão observados no cluster de municípios pouco estruturados, percebe-se grande variação, sendo o menor prazo de 405 dias e o maior prazo de conclusão de mais de 2 mil dias. O município mais célere do cluster foi o município fluminense de Nova Friburgo, que entregou mais de 2.200 unidades habitacionais, enquanto, no mesmo estado, o 
município de Pojuca entregou apenas 600 unidades habitacionais em um prazo de execução cinco vezes maior.

Quando analisamos os 10 municípios com o maior prazo médio de conclusão percebemos que apenas dois deles entregaram mais de mil unidades habitacionais no período, havendo uma possível associação entre maiores prazos de entrega e menores quantidades de unidades entregues. Esse fato pode denotar potenciais ganhos de escala na produção habitacional, em que empreendimentos maiores sejam executados de forma mais célere.

Ao todo, 733 municípios chegaram a firmar contratos para receber recursos do programa, no entanto, 624 conseguiram concluir seus empreendimentos dentro do período analisado (2012 a 2016). Desse universo de 624, apenas 42 compunham os clusters 5 e 6 (municípios muito pouco estruturados ou com estrutura mínima da classificação realizada anteriormente). Considerando que esse quantitativo não seria representativo desses grupos de municípios (clusters 5 e 6), pois retrata menos de $1 \%$ do universo de municipalidades muito pouco estruturadas ou com estruturas mínimas existentes no Brasil, optou-se por não considerá-las nessa etapa da análise. Dessa forma, essa etapa contou com uma amostra de 577 municípios.

Com o uso da Análise Envoltória de Dados - Data Enveloped Analysis (DEA), esses municípios foram classificados de acordo com sua eficiência relativa. Dessa amostra, 94 municípios foram considerados eficientes (conforme observamos na Tabela 3), o que representa 16\% dos municípios analisados, considerando a eficiência média do período (2012-2016).

\section{TABELA 3 DISTRIBUIÇÃO DE MUNICÍPIOS EFICIENTES NO MCMV POR PERFIL DO PLANO DIRETOR E PERFIL DE TAXAS INSTITUÍDAS}

\begin{tabular}{|c|c|c|c|c|}
\hline $\mathrm{N}^{\circ}$ & Cluster & Eficientes & Amostra & $\%$ Eficientes \\
\hline 1 & Muito bem estruturados & 23 & 77 & $30 \%$ \\
\hline 2 & Bem estruturados & 26 & 137 & $20 \%$ \\
\hline 3 & Medianamente estruturados & 19 & 132 & $16 \%$ \\
\hline 4 & Pouco estruturados & 26 & 231 & $12 \%$ \\
\hline
\end{tabular}

Fonte: Elaborada pelos autores.

Ao analisar os resultados da avaliação da eficiência relativa, considerando os grupos propostos pela classificação de municípios por perfil do plano diretor e perfil de taxas instituídas, percebe-se que o percentual de municípios eficientes cresce à medida que consideramos os cluster de municípios com características de melhor estrutura. O cluster 1 - municípios muito bem estruturados, com plano diretor atualizado e que arrecadam mais de três taxas (tributos vinculados à prestação de serviços específicos) - apresentou percentual de municípios eficientes superior ao dobro do cluster 4, que engloba municípios pouco estruturados, com plano diretor desatualizado e arrecadação de menos de três taxas (Tabela 4). 


\section{TABELA 4}

PERCENTUAL DE MUNICÍPIOS POR PERFIL DE EFICIÊNCIA NO PROGRAMA MCMV, PERFIL DO PLANO DIRETOR E PERFIL DE TAXAS INSTITUIDDAS

\begin{tabular}{|c|c|c|c|c|c|c|c|c|c|}
\hline \multirow[t]{2}{*}{ Cluster } & \multicolumn{2}{|c|}{$\begin{array}{l}\text { Eficiência } \\
\text { Escore (1) }\end{array}$} & \multicolumn{2}{|c|}{$\begin{array}{c}\text { Baixa ineficiência } \\
\text { Escore } \\
(1,01-1,10)\end{array}$} & \multicolumn{2}{|c|}{$\begin{array}{l}\text { Média ineficiência } \\
\text { Escore } \\
(1,10-1,25)\end{array}$} & \multicolumn{2}{|c|}{$\begin{array}{l}\text { Alta ineficiência } \\
\text { Escore } \\
\text { (acima de 1,25) }\end{array}$} & \multirow[t]{2}{*}{ Amostra } \\
\hline & Mun. & $\%$ & Mun. & $\%$ & Mun. & $\%$ & Mun. & $\%$ & \\
\hline 1 & 23 & $30 \%$ & 31 & $40 \%$ & 17 & $22 \%$ & 6 & $8 \%$ & 77 \\
\hline 2 & 26 & $19 \%$ & 35 & $26 \%$ & 46 & $34 \%$ & 30 & $22 \%$ & 137 \\
\hline 3 & 19 & $14 \%$ & 42 & $32 \%$ & 50 & $38 \%$ & 21 & $16 \%$ & 132 \\
\hline 4 & 26 & $11 \%$ & 79 & $34 \%$ & 98 & $42 \%$ & 28 & $12 \%$ & 231 \\
\hline
\end{tabular}

Fonte: Elaborada pelos autores.

Uma análise do resultado por cluster de municípios demonstra, ainda, que, no cluster 1, predominam a eficiência e a baixa ineficiência, com $70 \%$ dos municípios enquadrados nessas faixas de eficiência relativa; nos demais clusters predominam a baixa e média ineficiência, e a média ineficiência ocorre com mais frequência no cluster 4, cuja classificação aponta para menor capacidade de planejamento e arrecadação.

Como podemos observar na Figura 4, a alta ineficiência é mais frequente no cluster 2 - municípios bem estruturados, caracterizado por possuir plano diretor atualizado, mas capacidade de arrecadação reduzida, uma vez que recolhe menos de três taxas. Nesse caso, pode indicar que a capacidade de arrecadação afeta mais a eficiência relativa do que os aspectos ligados ao planejamento do município.

\section{FIGURA 4 PERCENTUAL DE MUNICÍPIOS POR PERFIL DO PLANO DIRETOR E PERFIL DE TAXAS INSTITUÍDAS E EFICIÊNCIA RELATIVA NO MCMV}

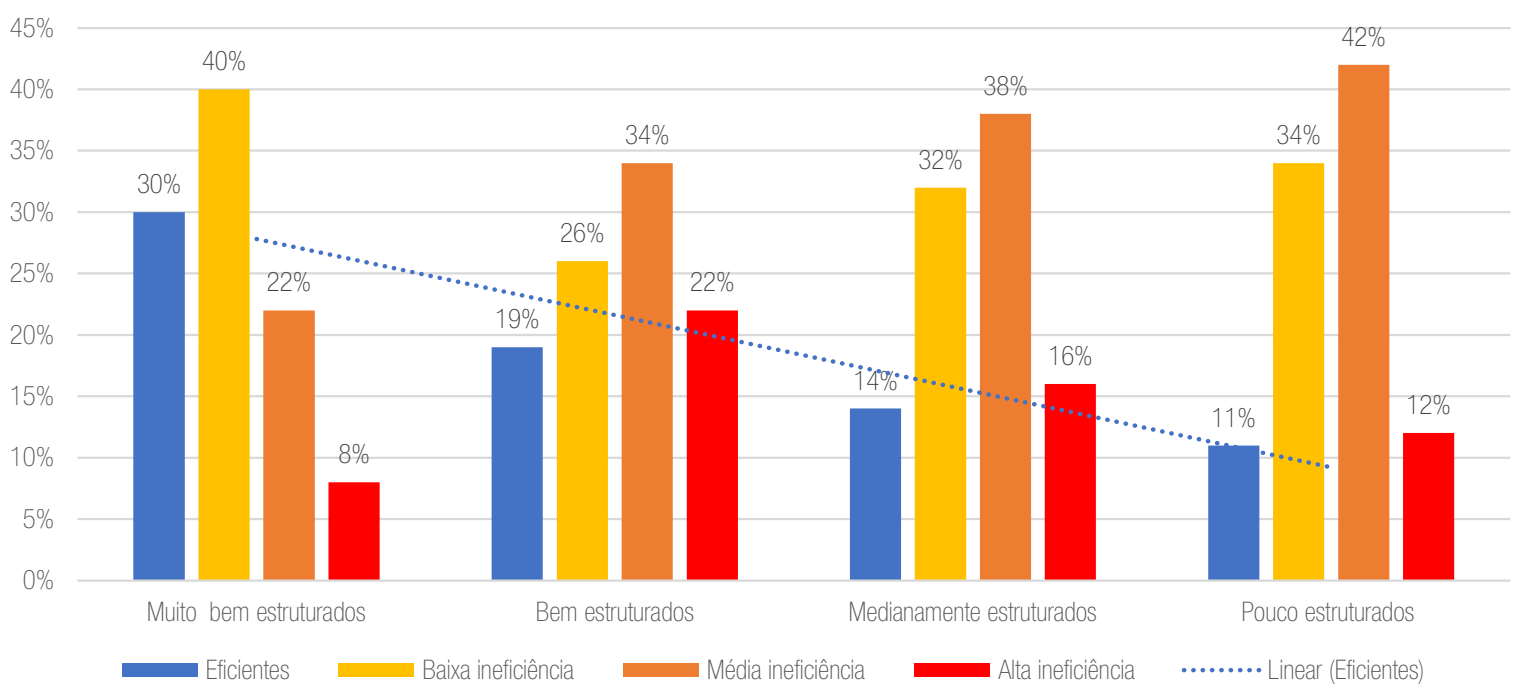

Fonte: Elaborada pelos autores.

Revista de Administração PÚblica | Rio de Janeiro 55(2): 309-330, mar. - abr. 2021 
Se analisarmos geograficamente a distribuição da eficiência média dos municípios, será possível perceber que a maior parte dos eficientes está situada nas regiões Nordeste e Sudeste, contudo, quando observamos a proporção de municípios eficientes por região, destacam-se as regiões Nordeste e Centro-Oeste, como demonstrado na Tabela 5. A região Centro-Oeste sobressai também por não ter apresentado municípios com alta ineficiência.

\section{TABELA 5 DISTRIBUIÇÃO DE MUNICÍPIOS POR REGIÃO E PERFIL DE EFICIÊNCIA RELATIVA NO MCMV}

\begin{tabular}{|c|c|c|c|c|c|c|c|c|c|}
\hline \multirow{2}{*}{$\begin{array}{l}\text { Região } \\
\text { Norte }\end{array}$} & \multicolumn{2}{|c|}{$\begin{array}{l}\text { Eficiência } \\
\text { Escore (1) }\end{array}$} & \multicolumn{2}{|c|}{$\begin{array}{c}\text { Baixa ineficiência } \\
\text { Escore }(1,01-1,10)\end{array}$} & \multicolumn{2}{|c|}{$\begin{array}{l}\text { Média ineficiência } \\
\text { Escore }(1,10-1,25)\end{array}$} & \multicolumn{2}{|c|}{$\begin{array}{c}\text { Alta ineficiência } \\
\text { Escore (acima de } 1,25)\end{array}$} & \multirow{2}{*}{$\begin{array}{c}\text { Amostra } \\
58\end{array}$} \\
\hline & 10 & $17 \%$ & 28 & $48 \%$ & 18 & $31 \%$ & 2 & $3 \%$ & \\
\hline Nordeste & 39 & $24 \%$ & 72 & $44 \%$ & 47 & $29 \%$ & 5 & $3 \%$ & 163 \\
\hline Sudeste & 21 & $10 \%$ & 31 & $15 \%$ & 83 & $41 \%$ & 67 & $33 \%$ & 202 \\
\hline Sul & 11 & $11 \%$ & 21 & $21 \%$ & 53 & $54 \%$ & 14 & $14 \%$ & 99 \\
\hline Centro-Oeste & 13 & $24 \%$ & 33 & $60 \%$ & 9 & $16 \%$ & 0 & $0 \%$ & 55 \\
\hline
\end{tabular}

Fonte: Elaborada pelos autores.

A maior parte dos municípios da amostra é da região Sudeste (202 municípios). Tal fator pode ser interpretado como positivo para o desempenho da região, uma vez que a amostragem levou em consideração apenas os municípios que concluíram os empreendimentos do programa Minha Casa Minha Vida entre 2012 e 2016. Contudo, a região apresentou o maior percentual de municípios com alta ineficiência: ao todo são 66 , o que representa $33 \%$ da amostra da região. E apenas $25 \%$ dos municípios do Sudeste demonstraram eficiência (10\%) ou baixa ineficiência (15\%), configurando o pior resultado regional.

A Figura 5 apresenta a distribuição dos diferentes perfis de eficiência dos municípios por região. Observa-se que as regiões Nordeste e Centro-Oeste apresentaram o maior percentual de municípios eficientes ou com baixa ineficiência - $68 \%$ naquela e $84 \%$ nesta. Outro desempenho que pode ser considerado positivo é o da região Norte, em que $66 \%$ dos municípios foram classificados como eficientes ou com baixa ineficiência. Por fim, na região Sul, a maior parte dos municípios (68\%) foi classificada com média (54\%) ou alta ineficiência (14\%). 


\section{FIGURA 5}

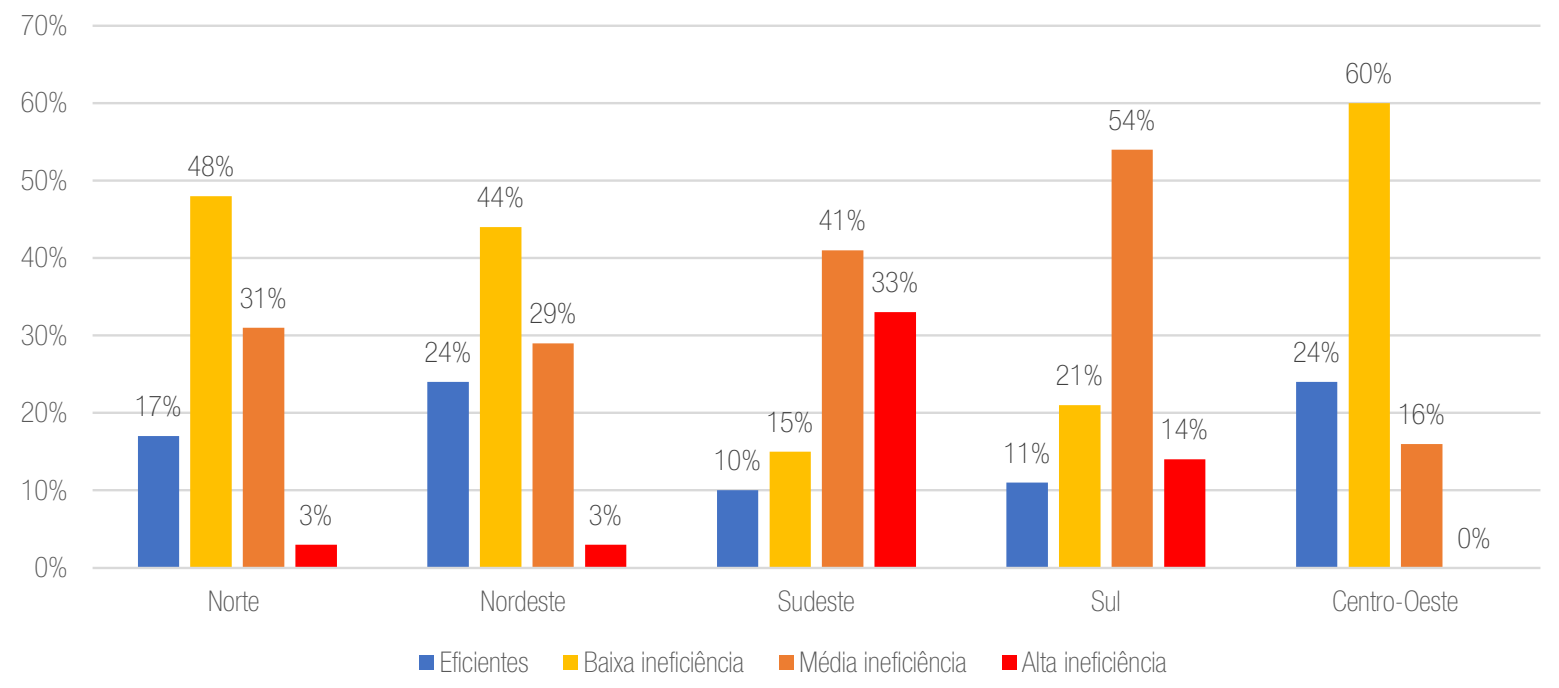

Fonte: Elaborada pelos autores.

Em suma, a análise dos resultados por cluster de municípios revelou evidências preliminares de que aspectos da estrutura dos municípios, como capacidade de planejamento e arrecadação, podem influenciar os resultados alcançados na implementação de políticas públicas, em especial pelos resultados alcançados pelo cluster composto por municípios muito bem estruturados.

Já a análise regional demonstrou resultados que podem ser usados para rediscutir o impacto da desigualdade regional na implementação de políticas, uma vez que as regiões Norte, Nordeste e CentroOeste apresentaram os melhores resultados. Cabe destacar que o próprio processo de amostragem pode ter influenciado o resultado apresentado, sendo está uma limitação da análise proposta, que avaliou apenas os municípios que concluíram os empreendimentos no período, ou seja, um número significativo de municípios não foi selecionado pela amostra. Caso seja realizada uma nova análise, com método capaz de analisar o desempenho em empreendimentos não concluídos, os resultados podem divergir.

Dessa forma, pode ser considerado uma revelação dos dados que a estrutura dos municípios (capacidade de planejamento e arrecadação) tenha uma influência maior em seus desempenhos do que o espaço geográfico no qual estão inseridos. 


\section{CONSIDERAÇÕES FINAIS}

Este trabalho teve como objetivo a avaliação da eficiência relativa dos municípios na execução do programa Minha Casa Minha Vida (MCMV). Para tanto, foram estabelecidas duas etapas de pesquisa. A primeira buscou classificar o conjunto de municípios em grupos homogêneos, revelando que a maior parte dos municípios brasileiros possui estrutura mínima ou pouca estrutura. Apenas $6 \%$ dos municípios brasileiros foram classificados como muito bem estruturados - os que possuem plano diretor atualizado e arrecadam mais de três taxas.

Outro achado importante é que os municípios com menos de 20 mil habitantes não possuem sequer estrutura mínima - mais de $58 \%$ destes não têm plano diretor e arrecadam menos de três taxas, mostrando que eles não contam com escala que proporcione seu funcionamento adequado em condições mínimas. Sendo essa uma importante agenda de pesquisa, com a necessidade de repensar o modelo federativo, criando possibilidades de novas composições de municípios que considerem o porte populacional como critério de agregação uma alternativa a ser avaliada.

Já a segunda etapa do trabalho buscou avaliar a eficiência relativa de municípios na execução do programa Minha Casa Minha Vida (MCMV). A qualificação da eficiência relativa na execução do MCMV mostrou que o percentual de municípios eficientes foi maior entre os classificados com melhor estrutura pela análise de cluster, configurando-se como superiores ao dobro na comparação de municípios muito bem estruturados com os pouco estruturados. Esse resultado corrobora a literatura sobre a modalidade Oferta Pública de Recursos do programa, que tem concluído que a capacidade técnica e institucional tem sido um obstáculo para melhores resultados do MCMV.

Já a análise regional apresentou as regiões Centro-Oeste, Nordeste e Norte como mais eficientes. Ao considerar que a eficiência relativa foi medida com base em dois importantes insumos - recursos financeiros e tempo para a conclusão dos empreendimentos -, é possível que essas regiões tenham se destacado na utilização dos recursos financeiros.

Tal fato pode ter relação com as características do setor produtivo da construção civil, um setor intensivo em mão de obra, e esse recurso é relativamente mais barato nas regiões Norte e Nordeste do Brasil. Dados da Câmara Brasileira da Indústria da Construção (CBIC) sobre o Custo Unitário Básico da Construção (CUB) por metro quadrado revelam uma importante variação regional. De forma geral, o CUB das regiões Norte, Nordeste e Centro-Oeste são 1\% a 4\% menores do que o CUB Brasil, enquanto nas regiões Sul e Sudeste ele varia de 3\% a 10\%, superior ao valor nacional. Cabe destaque ainda aos custos associados à aquisição do terreno, que possuem valores expressivamente mais baixos na maior parte dos centros urbanos das regiões Centro-Oeste, Norte e Nordeste do Brasil.

Outro ponto importante a considerar é a dinâmica de empreendimentos habitacionais no contexto urbano complexo das cidades brasileiras. Ao propor uma análise em âmbito nacional, aspectos importantes dos contextos locais não podem ser analisados. Sendo assim, ao utilizar o valor do empreendimento como indicativo de eficiência, projetos alocados distantes dos centros urbanos, com valores de terreno frequentemente mais baixos, podem ser favorecidos pela avaliação proposta, sendo essa uma limitação deste trabalho. Além disso, a discussão sobre a inserção urbana dos empreendimentos e os custos associados à implantação dessas moradias distante dos equipamentos de saúde e educação são pontos relevantes que devem ser contemplados em próximos estudos sobre o tema.

Ao perceber que os municípios mais estruturados alcançam maiores níveis de eficiência, pode-se concluir, ainda, que, no âmbito do programa, a estrutura dos municípios tem participação mais 
relevante no alcance da eficiência do que sua inserção geográfica. Entretanto, é preciso entendê-lo com cautela, uma vez que tanto a eficiência relativa no MCMV quanto a classificação dos municípios foram realizadas de forma bastante exploratória, demandando estudos mais robustos do fenômeno.

Por fim, conforme já destacado, a modalidade do Minha Casa Minha Vida, objeto deste trabalho, teve como foco a Faixa 1 do programa, financiado com recursos do FAR. O arranjo institucional do projeto dá grande protagonismo ao setor privado, cabendo à gestão municipal o controle de processos sob sua responsabilidade, como definição da área de habitação de interesse social nos planos diretores e a emissão do "Habite-se", por exemplo.

Dessa forma, as grandes disparidades nos prazos de execução podem indicar não só diferenças significativas no aspectos da gestão municipal, como também distinções importantes dos níveis de eficiência do setor privado, sendo, inclusive, influenciado por outras características desse setor produtivo. Entender o papel do setor privado nos resultados alcançados pelo programa e como sua dinâmica de atuação afeta políticas públicas como o MCMV se mostra uma importante agenda de pesquisa nesse contexto. 


\section{REFERÊNCIAS}

Aguiar, M. H. (2014). Políticas de provisão habitacional no Brasil: contradições e limites à integração social. Revista Tamoios, 10(2), 22-34.

Bandeira, L. F., Silva, R. M. P., Gonçalves, A. O., \& Calmon, P. C. P. (2015). Políticas públicas: análise bibliométrica da produção científica nos periódicos de administração no período de 2008-2013. In Anais do $39^{\circ}$ Encontro da ANPAD, Belo Horizonte, MG.

Carlantonio, L. M. (2001) Novas metodologias para clusterização de dados (Tese de Doutorado). Universidade Federal do Rio de Janeiro, Rio de Janeiro, RJ.

Carvalho, A. X. Y., Mata, D., \& Resende, G. (2007). Clusterização dos municípios brasileiros. In A. X. Y. Carvalho, C. W. Albuquerque, J. A. Mota, \& M. Piancastelli (Orgs.), Dinâmica dos municípios (pp. 326-368). Brasília, DF: Ipea.

Costa, F. L., \& Castanhar, J. C. (2003). Avaliação de programas públicos: desafios conceituais e metodológicos. Revista de Administração Pública, 37(5), 969-992.

Diel, E. H., Diel, F. J., Schuls, S. J., Chiarello, T. C., \& Rosa, F. S. (2014) Desempenho de municípios brasileiros em relação à estratégia de investimento público em educação. Desenvolvimento em Questão, 12(26), 79-107.

Dutra, W. Z. (2013). Entre a produção habitacional estatal e as moradias precárias: uma análise da popularização da casa própria no Brasil. Perspectivas em Políticas Públicas, VI(11), 131-154.

França, K. C. B. (2015) Os gargalos para a provisão habitacional em municípios de pequeno porte: análise do programa Minha Casa, Minha Vida. Urbe. Revista Brasileira de Gestão Urbana, 7(3), 325-339.

Howlett, M., McConnell, A., \& Perl, A. (2016). Moving policy theory forward: connecting multiple stream and advocacy coalition frameworks to policy cycle models of analysis. Research and Evaluation. Australian Journal of Public Administration, 76(1), 65-79.

Januzzi, P. M. (2005). Indicadores para diagnóstico, monitoramento e avaliação de programas sociais no Brasil. Revista do Serviço Público Brasília, 56(2), 137-160.
Klintowitz, D. (2016). Por que o programa Minha Casa Minha Vida só poderia acontecer em um governo petista? Cadernos Metrópole, 18(35), 165190. Recuperado de http://dx.doi.org/10.1590/22369996.2016-3508

Krause, C. (2012, maio 03). O programa Minha Casa Minha Vida em municípios de até 50 mil habitantes: quadro institucional e prognósticos da provisão habitacional de interesse social (Comunicados do Ipea, n. 146). Brasília, DF: Ipea.

Lins, M. E., Lobo, M. S. C., Silva, A. C. M., Fiszman, R., \& Ribeiro, V. J. P. (2007). O uso da Análise Envoltória de Dados (DEA) para avaliação de hospitais universitários brasileiros. Ciência \& Saúde Coletiva, 12(4), 985-998.

Lotta, G. S.; Gonçalves, R., \& Bitelman, M. (2014). A coordenação federativa de políticas públicas: uma análise das políticas brasileiras nas últimas décadas. Cadernos Gestão Pública e Cidadania, 19(64), 2-18.

Menezes, D. B. (2017). Provisão de habitação de interesse social nos municípios gaúchos: resultados de programas federais entre 2007 e 2016 . Indicadores Econômicos FEE, 44(3), 97-112.

Ministério do Planejamento. (2014). Balanço PAC 2 4 anos de execução - $11^{\circ}$ Balanço - 2011 a 2014. Brasília, DF: Autor. Recuperado de http://pac.gov.br/pub/up/ relatorio/f9d3db229b483b35923b338906b022ce.pdf

Oliveira, V. E. (2016). Saúde pública e políticas públicas: campos próximos, porém distantes. Saúde Pública e Políticas Públicas, 25(4), 880-894.

Pedroso, M. M., Calmon, P. C. P., Bandeira, L. F., \& Lucena, R. A. V. (2012). Eficiência relativa da política nacional de procedimentos cirúrgicos eletivos de média complexidade. Revista de Administração Contemporânea, 16(2), 237-252.

Peña, C. R. (2008). Um modelo de avaliação da eficiência da administração pública através do método Análise Envoltória de Dados (DEA). Revista de Administração Contemporânea, 12(1), 83-106.

Ramos, M. P., \& Schabbach, L. M. (2012). O estado da arte da avaliação de políticas públicas: conceituação e exemplos de avaliação no Brasil. Revista de Administração Pública, 46(5), 1271-294.

Reis, F. N. S. C. (2013). Programa "Minha Casa, Minha Vida”: estrutura lógica, focalização e percepção 
dos beneficiários (Dissertação de Mestrado). Universidade Federal de Viçosa, Viçosa, MG.

Rolnik, R., Iacovini, F. G. R., \& Klintowitz, D. (2014). Habitação em municípios paulistas: construir políticas ou "rodar" programas? Revista Brasileira de Estudos Urbanos e Regionais, 16(2), 149-165.

Sano, H., \& Montenegro, M. J. F., Filho. (2013). As técnicas de avaliação da eficiência, eficácia e efetividade na gestão pública e sua relevância para o desenvolvimento social e das ações públicas. Desenvolvimento em Questão, 11(22), 35-61.

Silva, C. F., \& Alves, T. W. (2014). Dinâmica dos financiamentos habitacionais nos municípios do Rio Grande do Sul de 2006 a 2010: uma avaliação do Programa "Minha Casa, Minha Vida". Revista de Administração Pública, 48(1), 27-54. Recuperado de https://doi.org/10.1590/S0034-76122014000100002

Silva, M. C., Silva, J. D. G., Borges, E. F., \& Souza, F. J. V. (2015). Ranking de desempenho de municípios: elaboração de um único índice a partir do IDHM, IFDM e IRFS. Veredas Favip, 8(1), 62-78.

Souza, C. (2003). "Estado do campo" da pesquisa em políticas públicas no Brasil. Revista Brasileira de Ciências Sociais, 18(51), 15-20.

Varela, P. S., Martins, G. A., \& Fávero, L. P. L. (2012). Desempenho dos municípios paulistas: uma avaliação de eficiência da atenção básica à saúde. Revista de Administração, 47(4), 624-637.

Vedung, E. (2010). Four waves of evaluation diffusion. Evaluation, 16(3), 263-277. Recuperado de https://doi.org/10.1177/1356389010372452

Veloso, J. F. A., Monasterio, L. M., Vieira, R. S., \& Miranda, R. B. (2011). Uma visão inicial dos subsistemas da gestão pública municipal. In J. F. A. Veloso, L. M. Monasterio, R. S. Vieira, \& R. B. M. (Orgs.), Gestão municipal no Brasil: um retrato das prefeituras (pp. 11-40). Brasília, DF: Ipea.

\section{Ludmila Ferreira Bandeira}

https://orcid.org/0000-0002-7020-600X

Mestre em Administração Pública e Políticas Públicas pela Universidade de Brasília (UnB); Economista da Secretaria Nacional de Habitação do Ministério do Desenvolvimento Regional (SNH/MDR).

E-mail: ludmilafbandeira@gmail.com

\section{Edgar Reyes Junior}

https://orcid.org/0000-0001-7403-5909

Doutor em Administração pela Universidade do Vale do Rio dos Sinos (Unisinos); Professor adjunto da Universidade de Brasília ligado ao Programa de Pós-Graduação em Administração (PPGA/UnB).

E-mail: prof.edreyes@gmail.com 